\title{
Virtual Learning for Persons with Visual Impairment: An Exploration of Learning Platform in a Home Environment from UTH Special School in Lusaka, Zambia
}

\author{
E. Mwanza, M. Simalalo, and F. Simui
}

\section{ABSTRACT}

\begin{abstract}
The purpose of this study was to explore the accessibility of virtual learning platforms for person with visual impairment in the home environment. The study was qualitative in nature and took the form of a case study design. Purposive sampling was used to sample fifteen participants who took part in the study. Emergent from this study was a cluster of digital tools in use such as WhatsApp, Zoom, Google Meet/ Classroom, or Email applied to access virtual learning. In addition, computers with JAWS, smart phones with speech reader and readily available internet facility, some radios and TVs were required for virtual learning at home. The study found accessibility of virtual learning in a home environment depended on internet connectivity and having rightful gadgets which were user-friendly to individual with visual impairment as well as low socio-economic background as it determined the purchasing power. Further, challenges faced included children's lack of computers and phones with bundles to go online, poor internet connectivity and unconducive home environment. The study also revealed that parents needed social support and financial support from well-wisher like donor community and government to support them with ICT gadgets specifically designed for children with visual impairment. Besides, they need internet services and with ITC gadgets instilled with speech readers or JAWS. Thus, the study suggested among others, that teacher should start using video and audio-conferencing teaching, open up virtual resources Centre for learners, strength the collaboration between teacher and parents and make pricing of ICT equipment affordable for the visually impaired.
\end{abstract}

Keywords: Home Environment, Platforms, Virtual Learning, Visual Impairment.
Published Online: November 26, 2021

ISSN: $2736-4534$

DOI :10.24018/ejedu.2021.2.6.196

\section{E. Mwanza}

University of Zambia

Institute of Distance Education

Lusaka, Zambia

(e-mail: esnartmwanza13@gmail.com)

M. Simalalo

School of Education,

University of Zambia

Lusaka, Zambia.

(e-mail: magdalene.simalalo@unza.zm)

F. Simui*

University of Zambia

Institute of Distance Education

Lusaka, Zambia

(e-mail: francis.simui@unza.zm)

*Corresponding Author

\section{INTRODUCTION}

The history of virtual learning starts around early 1960s when the University of Illinois established a classroom system equipped with linked computer terminals. Students could access informational resources on a particular course while listening to the lectures. The 1970s and 1980s saw notable contributions in computer-based learning by researchers at the New Jersey Institute of Technology as well as developments at the University of Guelph in Canada (Salmon, 2013). In 1976, Bernard Luskin established Coastline Community College as a "college without walls" by using the television station KOCE-TV as a medium of delivery. By the mid-1980s, course materials became accessible via the libraries at many colleges. With the emergence of the World Wide Web into the public domain in the 1990s, academics started using newly introduced technologies to employ multi-object-oriented sites (which are text-based online virtual reality systems) to create course websites along with simple sets of instructions for their students. Improved Internet functionality and speed enabled new methods of communication involving multimedia, interactive material or webcams (Salmon, 2013).

Virtual learning involves learning that functionally and effectively occur in the absence of traditional classroom environments (Bulman \& Fairlie, 2016). A system that offers educators digitally- based solutions aimed at creating interactive, active learning environments. Virtual learning, adopts different principles and criteria to what is common to traditional education (Redmond, 2011). This new approach is based on digital computers and communication lines rather than on timely physical existence in a class (Muleya et al., 2019). Hence, the need to find out on the forms of virtual learning being utilized in a home environment with learner with visual impairment.

With sudden outbreak of a deadly disease called Covid-19 
caused by a Corona Virus (SARS-CoV-2) shook the entire world, many academic institutions that were earlier reluctant to change their traditional pedagogical approach had no option but to shift to virtual teaching and learning (Affouneh et al., 2020). But amidst this crisis, there seem to be no other alternative left other than adapting to the dynamic situation and accepting the change (Affouneh et al., 2020). What is not fully established is how the learners with visually impairment access learning platform in a home environment.

Zambia, like most countries in the world, ordered all schools to close to try and stop the spread of COVID-19. Many schools also asked parents to ensure that learning continues at home. The philosophy underlying at-home learning is the creation and provision of alternative educational opportunities, as well as the open access to these opportunities for everyone so that the ideal of home learning may be fulfilled (Johnson-Jones, 2017). Home environment is the most powerful informal learning situation in which the families, especially parents, act as educators (Kaisara \& Bwalya, 2021). Despite these facts, accessibility of virtual learning platforms for a person with visual impairment in the home environment has largely been under-explored in the scholarly literature. It is imperative to conduct this study to fill the information gap mentioned above.

According to Simalalo (2017), Chipili et al. (2018), and Simui et al. (2017), Learners with visual impairment are among the most vulnerable, facing multiple forms of exclusion linked to education. Coupled with the COVID-19 pandemic, learners with VI have been left entirely unsupported and excluded from the education system. With COVID-19 pandemic, many countries relied on technology to mitigate learning loss (Mahyoob, 2020). The Zambian government took an immediate action to ensure educational services are delivered during the COVID-19 crisis. In response to COVID-19, the focus of learning automatically shifted to parents and families to support home-based learning for their children. Accessibility of learning platforms for learners with visual impairment in a home environment, especially during lockdown for Covid-19 leaves much worries on how learners with visual impairment were catered for by not leaving anyone behind. No known research in Zambia has managed to determine clearly the learning platform used by students with visual impairment in a home environment. As a result, very scant research investigates the virtual learning experiences of visual impairment users in home environment. This study attempts to fill this gap in research, especially in the Zambian context.

\section{A. Statement of the Problem}

The COVID-19 pandemic swept the world more quickly than many expected, leaving education systems unprepared on how to implement virtual and at-home learning (Affouneh et al., 2020). Affouneh et al. (2020) posits that home environment is as important as what goes on in the school. Lack of accessibility in the design of virtual learning courses continues to act as an obstacle in the learning way of students with visual impairment (Pogrund, 2018). Notwithstanding these alarming trends, the gendered dimensions of incapacitation towards persons with visual impairment has largely been under-explored in the scholarly literature on virtual learning. One of the most prominent problems is that virtual learning is not specifically designed for vision impaired students (Ruchi, et al., 2013). Hence, the need for this study to explore the accessibility of virtual learning platforms for persons with visual impairment in a home environment in selected schools catering for learners with visual impairment.

\section{B. Purpose of the Study}

The purpose of the study was to explore the accessibility of virtual learning platforms for a person with visual impairment in the home environment.

\section{Objectives of the Study}

The objectives of the study that guided the study are:

i. To describe forms of teaching and learning of virtual learning being utilised in a home environment for person with visual impairment.

ii. To explore the determinants of accessibility of virtual learning in a home environment.

iii. To explore the alternative interventions in use on virtual learning for person with visual impairment.

\section{Theoretical framework}

This study was inspired by theoretical insights from the unified theory of acceptance and use of technology (UTAUT), a technology acceptance model formulated by Venkatesh and others in "User acceptance of information technology (Chipili et al., 2018). The UTAUT aims to explain user intentions to use an information system and subsequent usage behaviour. The theory holds that there are four key constructs: 1) performance expectancy, 2) effort expectancy, 3) social influence, and 4) facilitating conditions. The theory was developed through a review and consolidation of the constructs of eight models that earlier research had employed to explain information systems usage behaviour (theory of reasoned action, technology acceptance model, motivational model, theory of planned behaviour, a combined theory of planned behaviour/technology acceptance model, model of personal computer use, diffusion of innovations theory, and social cognitive theory).

\section{METHODOLOGY}

\section{A. Research Design}

This study was designed in line with qualitative research approach. For this particular research a case study approach or exploratory study was chosen. A case study or exploratory study was found to be ideal for this particular study as it brings out facts and insights about the topic under investigation. It was grounded on the interpretive paradigm. Rooted in the interpretive paradigm, the researcher explored the accessibility of virtual learning platforms for person with visual impairment in the home environment (Creswell, 2014).

\section{B. Population and sample size}

The study' s target population comprised head teachers, parents for, and learners with visual impairment. The researcher does not have a predetermined sample size but during the data collection phase reached point of data saturation after a sample of fifteen participants when no new information were coming forth. That is how the sample size 
was arrived at and it comprised of one Head teacher, seven parents and seven learners with visual impairment.

\section{Sampling procedure}

Homogeneous purposive sampling was used to select parents who had children with visual impairment and their children. For the head teacher critical case sampling was used because the respondents are critical cases that could contribute the most useful information for the study.

\section{Research Instruments}

The research instruments that were used in this study included semi-structured interview guide and Focus Group Discussions guide. Therefore, semi-structured interviews were used as they intensively investigate a particular topic. The interview method allowed the researcher to seek clarity and probe for deeper understanding. Focus Group Discussions was used to solicit information from pupils.

\section{E. Data collection procedure}

At the participating school, verbal permission was obtained from the head teachers to use their facilities before proceeding with data collection. The semi-structured interview guide was administered by the researcher to the interviewees and the FGD was also conducted by the researcher. The researcher conducted a face-to-face interview with head teachers and parents. Further, Focus Group Discussions was conducted with learners on their virtual learning experience. Voice recorder was used to record the conversations to capture the opinions and views of the participants in order to help transcribe them from voice to ink messages for data analysis.

\section{F. Data analysis}

As regards data analysis, collected data was analysed using thematic analysis (Patricia, 2017). The analysed data was presented descriptively; voices of the participants to support the findings were employed in some cases. Pseudonyms names was used to show actual verbatim such as for Parents P1, P2 $\cdots \mathrm{P} 7$ and for learners L1, L2 $\cdots \mathrm{L} 7$ and the head teacher by virtue of the office the HT were used.

\section{G. Ethical considerations}

Before going in the field for data collection, permission was obtained from UNZA Ethics Committee and an introductory letter from the Assistant Director Postgraduate at the Institute of Distance Education. Permission was also obtained the District Education Board Secretary (DEBS), school managers and participating parents and children. In order for the participants to get involved in the study, they gave consent. To ensure that confidentiality was upheld, respondents were assured that their names would remain anonymous. Respondents were referred to using pseudonyms to maintain their anonymity.

\section{FINDINGS AND DISCUSSION}

The findings were deduced from data which was collected using face-to-face interviews and observation check-list. The chapter presents the findings in line with the study questions which were as follows:

i. What forms of teaching and learning of virtual learning being utilised in a home environment for person with visual impairment?

ii. What are the determinants of accessibility of virtual learning in a home environment?

iii. What are the alternative interventions in use on virtual learning for person with visual impairment?

\section{A. Forms of teaching-learning of virtual learning utilized in a home Environment}

In an attempt to understand the forms of technology facilities being used by learners with visual impairment during virtual learning at home. Findings showed WhatsApp on the phone came out to be one form of technology which children with visual impairment were using to support their virtual learning in a home environment. Other parents indicated Facebook Messenger, Google Classroom, zoom has some of the convenient forms of virtual learning facilities they use with their children with visual impairment at home. In support of the findings above, participant (P2) had this to say:

The teacher has been sending work and other assigned tasks for my child on my phone. The teacher uses WhatsApp for conducting lesson with my child; and some works are sent on my email, (P2, 2021).

Contributing on the same participant (L3) had this to say during focus group discussion:

I use the smart phone for mum when I want to ask something from teacher and teacher know phone number for mum so he sends work using mum's phone.

Participant (P5) interviewed said:

With my son the teacher likes using Zoom on my phone. Using my phone my child is able to engage with the teacher and raises questions to the teacher. When we experience slow connections, the teacher even writes the important messages on chat boards. With this platform, child feel comfortable and easy to learn.

Another theme that emerged from the findings was the use of Zoom, google meet/ classroom or email on computer. Those children with computer at home where accessing virtual learning were using zoom, google classroom to have discussion with their teacher and sometime the teacher could email the work. This confirmed by participant (L3) during focus group discussion:

My teacher used to teach me using Zoom or google Classroom when Zoom has a problem. I download work sent to me on email and put on the computer for me to be reading from there.

Contributing to the same subject; the participant (HT) had this to say:

This children with visual impairment need a computer, laptop or smart phone with speech reader with instilled software like WhatsApp, zoom, google meet or Facebook messenger.

Another great theme that emerged from the findings was the use of radio and television to access virtual learning organized by government through nation broadcasting media. In support participant (P1) indicated that:

My child just listens to those lessons on Edu.TV on Zambia national broadcasting services since they closed school and there is another radio which 
broadcast the lesson for different grade although I don't know the timing for each grade.

Contributing on the same another participant (P4) had this to say:

As at now we can say that yes there are these radios and TVs but not all of our learners benefit from these facilities. We need a writing frame and braille paper to use at home. Because sometimes the teacher sends the work which needs to listen to and able to write them down.

The findings show that the majority of the participants accessed learning material through WhatsApp, Zoom, Google meet, and Email installed on phone and computer and use of radio and TV in accessing online lessons. This finding is also in line with the findings of Alturise (2020) who indicated that student used platforms such as emails for submitting their assignments, Microsoft teams, Google, and Zoom platform for conducting some lectures. The findings also resonate well with Bulman and Fairlie (2016) who revealed that most required ICTs facilities include hardware and software that matches the user needs and preferences of the visually impaired students to facilitate their learning and allow them to participate effectively in an inclusive learning environment. It was found that children with computer at home who were accessing virtual learning were using zoom, google classroom to have discussion with their teacher and sometime the teacher could email the work. The findings were agreeable with Aboagye et al. (2020) who said Google Classroom is one of the best platforms which could be accessed for free by an individual member. Some parents stressed that Google Classroom, Zoom are some of the convenient forms of virtual learning facilities they would use with their children with visual impairment at home. These findings are in line with Pauline and Raj (2018) findings who said Google Meet has similar features with Zoom. Another great theme that emerged from the findings was the use of radio and television to access virtual learning organized by government through nation broadcasting media. The findings of the study are positively linked to those of Kaisara and Bwalya (2021) who reported that the use of radio and television broadcast as virtual learning solutions is a powerful way to bridge the digital divide in the education sector and reach the most marginalized learners. This finding is also in line with Fairlie and Robinson (2013) and Simui et al. (2018) who stated in his study that visually-impaired students can gain access to many learning materials through special assistive technology that allow them to take notes, read and answer examination questions. The findings generally showed that some children with visual impairment had access to a phone or computer where WhatsApp, zoom were mostly used to access learning during this covid-19 school closure in the home.

\section{B. Determinants of accessibility of virtual learning in a home environment}

This objective was trying to ask participants on the determinants of accessibility of virtual learning in a home environment. It was found that some families had access to technology like computer with internet, smart phones, TV and radios. That is having a computer or smart phone which user-friendly. In support, participant (P7) had this to say: When having assistive technology like smart phone, $T V$, computer; they help a lot since the child does not need to move to a far place to learn. A child will still learn while at home by using the type of ICT facility someone has.

Contributing to the same subject, another participant (P2) had this to say:

The positive experience of accessing virtual learning in a home is that the child will not miss out on learning. The child is able to access education within the comfort of the home environment by using a phone. This reduces the time spent on going to and from school

Also, participant (L3) during focus group discussion said: It was helpful since I was able to learn at home. Dad bought a computer for me to be using.

Internet connectivity came out has an emerging theme. For everyone to access virtual learning content you need to be connect to internet. One needs to have data bundles. In support, participant (HT) had this to say:

I think, there is need to have internet connection on a computer or smart phone, which is not easy for most of the parents again. But teachers were encouraged to find means to continue interacting with learners as they are home by sending work to children through WhatsApp on phones and emails. Those who are teaching examination class were even using zoom to teach the learners who have access to zoom through their parents' phones.

To those children coming from well to do families noted that virtual learning is convenience as it enables a person to experience less trouble accomplishing a task, or possibly a lighter schedule or workload. On the other hand, those child with visual impairment from low socio-economic background never accessed virtual learning during covid-19 school closure. Participant (P5) commented that:

With me, think parent respond to the needs of their children according to their financial capacity. Some of our fellow parents were able to buy what was needed for their child with visual impairment to access online learning, but some of us, money is hard to find, you can see only have a small phone, I can manage to buy a smart phone. But my wish is to have a computer or tablet for her to be using.

As beneficial the virtual learning in a home environment to learners with visual impairment during the covid-19 pandemic, there were still some noticeable challenges. As most of the parent are coming from a low background it difficult to have enough recourses to buy ICT facilities for child with visual impairment. There are also some other issues that the learners faced, such as, high cost of ICT facilities and parents lack resources to purchase them. Some of the views given by the participants, for example, included the following as indicated in transcribed verbatim, participant (P1) said:

It is very difficult to improve on the learning of my child through virtual learning as most of the parent with these children are like me, we are vulnerable, and we can't manage to buy these equipment. Also, to some parents and our children it new so they 
know nothing about it.

Poor internet access hinders student access to virtual learning platforms. Children faced issues to do with internet speed, online access due to poor network, high cost of data, participant (L4) has this to say:

Lack of internet buddle and lack of electricity.

Internet is sometimes so slow that you end up

leaving the work you were doing

Another participant (L6) said:

The problem that I face is internet connection, because I don't have enough money to buy airtime. Most of time I used find that my parent they don't have money to buy data bundle for me. My parents are not working to buy a device for accessing internet

Yet another participant (L7) had this to say:

The problem that I will face is internet connection, because I don't have enough money to buy airtime, my parents are not working to buy a device for accessing internet

Contributing to the same subject; participant (HT) had this to say:

The major challenge is that of internet connectivity, the internet is not reliable. As I earlier alluded the other challenge is that these learners are coming from the vulnerable households, where parents cannot afford to buy these things.

The challenges faced by children with visual impairment in a home environment were not only technology related, but also social factors had an impact on how they experienced virtual learning. Some respondents indicated that their home environments where they stay is not conducive for learning. In support of this view, participant (L2) stated that:

Some of us stay in noisy places, not finding a quiet place. And the facilities I have to access virtual learning are shared at home so my time to be online is very limited.

Contributing to the same subject; participant (P1) commented that:

Some of us stay in noisy places. Not finding a quiet place when it come for my son to study.

Further, children with visual impairment had limited access to peer support. However, during online studies where students stay apart, it is difficult for students with visual impairment to access the support of their sighted peers which affect their use of virtual learning platforms. These were some comments of participant (L5):

During face-to-face instructions, our friends in the same classroom give support by explaining concepts to us which make our learning easy as compared to the virtual learning where every child is at his/her home. Peer support is very important in every academic endeavour but we students with visual impairment lost that opportunity during the virtual learning.

The following themes emerged under the determinants of accessibility of virtual learning in a home which include rightful or appropriate gadgets, internet connectivity, socioeconomic background, low socio-economic background, poor internet connectivity, unconducive home environment and limited access to peer support. The determinants of accessibility of virtual learning in a home environment found was having rightful gadgets. That is having a computer or smart phone which user-friendly. Parent noted that having assistive technology like smart phone, TV, computer they help a lot since the child does not need to move to a far place to learn.

In support of these findings, Romney and Celeste (2015) study found internet connectivity, for everyone to access virtual learning content you need to be connect to internet. One needs to have data bundles (Muwanguzi \& Lin, 2010). While others need radios and TVs so that they can benefit and listen to those lesson provided on those platforms by the ministry of general education. The findings above are in tandem with Bates (2016) study, which indicated that educational radio and television can support the millions of children who lack access to the internet or have low digital literacy. On the other hand, those child with visual impairment from low socio-economic background never accessed virtual learning during covid-19 school closure. It was found that children had no ICT facilities of their own, high cost of data and high cost of ICT facilities were among challenged faced by children with visual impairment to access virtual learning. This was in line with Global Voices (2020), who revealed that poor access to ICTs facilities and other services hamper the optimal learning of the visually impaired students. This is also in agreement with Henaku's (2020) study that students experience internet connectivity problems, financial difficulty due to the high cost of internet bundle in the use of virtual platforms for teaching and learning.

As most of the parent are coming from a low background it difficult to have enough recourses to buy ICT facilities for child with visual impairment. Some of the views given by the participants for example, parent said it is very difficult to improve on the learning of my child through virtual learning as most of the parent with these children are vulnerable, and they can't manage to buy these equipment. In support of this view, Ilonga et al. (2020) noted that the cost of ICTs facilities such as laptops and other assistive technologies required to enable visually impaired students' effective learning are too expensive for many students from poor backgrounds without gainful employment to afford them.

\section{Alternative interventions in use on virtual learning for person with visual impairment}

The findings showed that parents were in need of social support from well-wisher like donor community and government to support them with ICT gadgets specifically designed for children with visual impairment. In support of this participant (P7) indicated:

Our wish is for Donors to come on board to give parents computer or smart phones that can be used at home by our children with visual impairment. To buy more learning aids which they can be using at home to enhance accessibility and usage of virtual learning.

In support of this view, participant (P4) stated that: We need the provision of internet services to learners with visual impairment and with ITC gadgets instilled with speech readers or JAWS.

In support, participant (HT) had this to say; 
We need a donor who can provide these children with computer, iPad or phones with speech reader and free internet as some of us we can afford them. Also books in braille and in large print of those with low vision. We also need a Perkins brailler since using a writing flame becomes tedious, writing is also important we also need braille paper.

The findings showed that parents cannot provide the needed resources for virtual learning to their children on their own, they need help from cooperate world if they had to buy the needed ICT facilities for learner with visual impairment. For example, participant (L4) stated that:

I don't work, what am asking from people who can

help me with money so that I can buy what is required for my child to be learning online

Contributing to the same subject; participant (L2) had this to say:

I need money, I need support in buying of computer or smart phone to use, with support of buying of bundles.

The results shows that parent need much support from well-wishers or donors who can in supply them with ICT and assistive technology for children with visual impairment which they can be using in the home environment.

In an attempt to further establish a lasting solution to virtual learning among individual with visual impairment. From the results when it comes to online learning, it demands improved utilizing of technology is absolutely crucial for it to succeed. Some of the best ways teachers can use technology to help create great learning environments for their students include conferencing. In support of the view, participant (P7) indicated:

Teacher can start using video and audioconferencing systems using a smart phone, which I believe parents have phones, a teacher can explain concepts in a way that learners can understand just online while at home.

Contributing to the same subject; participant (L1) had this to say:

My teacher should continue teaching using conferencing. It was bring the class together as he used to teach us at one by audio call

Some parents proposed that teachers should open up virtual resources Centre for learners to log on and chat or download work for themselves. Chat channels can allow students to discuss things with their online class and have easy ways to connect even when they are far apart. In support of the findings, participant (P6) said:

I think teachers can just open up work bank in audio and video formant on the internet were the teacher can be positing work for the children and children can be accessing information or school work direct from there.

In view of this, participant (HT) commented that: With time, I this we planning when we open the website, we have to a part where teacher can be uploading the work both in text and audio according to grades, were children be downloading to read while at home.

Findings showed that working with parents and talking to them often can help them feel successful as they help their learner navigate the lockdown due to covid-19. Participant (P5) said:

I think this is the time the teachers and us parents for these children with visual impairment we need to work together because some of the things (ICT and assistive technology) we need for my child to be using when learning online I don't know them, so the teacher should orient me on what I should have or buy for my daughter to continue learning here at home.

Another theme that was cited is argent need on improve on lesson content presentation being aired on ZNBC. There is a lot of irregularities to how lesson a presented to make learners with visual impairment understand. In contribution, participant (P6) had this to say:

There is need improve on content of lesson by teachers who teaches on TV. In that part shall appreciate and will say boss you are moving in the right direction for our children with visual impairment.

The ICT equipment for children with visual impairment to use for virtual learning are expensive. Participant (HT) suggested that:

There is need to encourage the procurement of ICT equipment for learners with visual impairments at discount price. Also, there is need of partnership with internet service providers to provide internet services to learners with visual impairment. Engage teachers who have need trained in handling learners with visual impairment with ICT and raise an awareness on parents to buy smart phones and bundles for their children with visual impairment to be accessing virtual learning

The following themes emerged under alternative interventions in use on virtual learning for person with visual impairment such as social support, financial support, conferencing lesson presentation, creation of virtual resources centre, promote parental involvement, improvement in lesson content presentation, and lowering prices on ICT equipment for VI. This finding is also in line with IFS (2020), Mwase et al. (2020) and Mooka et al. (2020) who indicated that there is need for a donor who can empower the parents to children with visual impairments in terms of providing computers and smart phones for their children with visual impairment to use for online learning at home. Further, the findings showed that parents don't have money, to use toward buying even a smart phone to use to access virtual learning. In bridging the virtual gap for the visually impaired there is the need to provide assistive technologies.

In an attempt to further establish a lasting solution to virtual learning among individual with visual impairment, participants were asked on what they think should be done to improve the delivery of education through virtual learning for learners with visual impairment. From the results when it comes to online learning, it demands improved utilizing of technology is absolutely crucial for it to succeed. Parents suggested to teachers to be utilizing a variety of technology options. Teacher can start using video and audioconferencing systems using a smart phone, which is believed parents can afford phones. The findings agreed with 
Muwanguzi and Lin (2010) revealed that conferencing can be used to support interactive learning or student-centered teaching and learning in a team-oriented, virtual environment. Pauline and Raj (2018) stated that video conferencing boosts productivity, saves time, reduces travel expenses, and overall promotes collaboration.

Some parents proposed that teachers should open up virtual resources Centre for learners to log on and chat or download work for themselves. Findings resonated well with Bulman and Fairlie (2016) who revealed that a website or blog could serve as the main information center for a school or classroom. Teachers could use websites or blogs to disseminate assignments and assessments to students, as well as to facilitate discussions among students. Bates and Sangrà (2011) revealed that virtual resources Centre provide an opportunity to integrate the learning that is done online and, in the classroom, so that students can see clear connections between what they are doing in both environments.

Further, another vital theme that emerged during the interview was parental involvement. Working with parents and talking to them often can help them feel successful as they help their learner navigate the lockdown due to covid19. The findings were agreeable with Simui (2018) who said the promotion of local partnerships by each community is also very important. This concurs Wagner et al. (2008) who espouse that e-Learning makes available extra prospects for interactivity between students and teachers during content delivery (Kaumba et al., 2021). Furthermore, findings indicated that government should make radios, TVs, phones accessible to each and every individual by the virtual of doing that maybe removing taxes so that those parents who are poor to afford them. Also there is need improve on content of lesson by teachers who teaches on TV. The results of this study are in line with Bates (2016) who revealed that the value of educational broadcasts through television and radio also goes beyond the needs of students alone. In some countries, these programs are conceived to provide intergenerational learning, including in local languages.

\section{CONCLUSION}

Based on the findings and in line with the objectives; on the first objective study found that computers or smart phone that enables them to access the internet and their online learning which had screen readers, or uses a screen magnifier which has also been installed with WhatsApp, zoom, google meet/ classroom or email. Accessibility to virtual learning was determined by the type of learning platform someone in a home environment. Children with visual impairment require computers with JAWS, smart phones with speech reader and readily available internet facility for using virtual learning environment at home. Further, accessibility of virtual learning in a home environment depend on internet connection and having rightful gadgets which are userfriendly to individual with visual impairment as well as low socio-economic background as it determine the purchasing power. With regard challenges faced to access virtual learning in a home environment include lack of computer or phone with bundles to go online, poor internet connectivity, due to low background it difficult to have enough recourses to buy ICT facilities for child with visual impairment, unconducive home environment and lack of peer support. Furthermore, parents need social and financial support from well-wisher such as donor community and government to support them with ICT gadgets specifically designed for children with visual impairment. Child with visual impairment need internet services and with ITC gadgets instilled with speech readers or JAWS. Teacher should be using video and audio conferencing teaching, open up virtual resources Centre for learners to log on and chat or download work, to strength the collaboration between teacher and parents and of lowing prices on ICT equipment for the visually impaired.

\section{RECOMMENDATIONS}

Based on the findings, and in line with the study objectives, the following recommendation were made:

i. There is need of raising an awareness on parents to know the form of ICT and assistive technology facilities for the visually impaired children can use to access virtual learning at home.

ii. The parent should shoulder their responsibilities of providing appropriate state-of-the-art ICT-based facilities like computer, smart phones and access to internet connectivity to enable the visually-impaired children to access and use virtual learning at home.

iii. There should be successful collaboration between the different stakeholders and parents sharing of responsibilities to foster education excellence for the visually-impaired students.

iv. In relation to this study, it is suggested that the study should be replicated on a national scale, and that it should include a large sample of respondents focus on other disabilities like hearing impairment, intellectual disability, autism, and the deaf blind to have a national picture and elevate the generalisability of findings.

\section{CONFLICT OF INTEREST}

Authors declare that they do not have any conflict of interest.

\section{REFERENCES}

Aboagye, E., Yawson, J.A, Appiah, K.N. (2020). COVID-19 and elearning: the challenges of students in tertiary institutions. Social Education Research, 1-8.

Affouneh, S., Salha, S.N., Khlaif, Z. (2020). Designing quality elearning environments for emergency remote teaching in coronavirus crisis." Interdisciplinary Journal of Virtual Learning in Medical Sciences, 11(2), 1-3.

Alturise, F. (2020). Evaluation of the Blackboard Learn Learning Management System for Full Online Courses in Western Branch Colleges of Qassim University. International Journal of Emerging Technologies in Learning, 15(15), 33-50.

Bates, A.W. (2016). Automation or empowerment: online learning at the crossroads (Junhong Xiao trans.). Distance Education in China, 4, 5-11.

Bates, T., \& Sangrà, A. (2011). Managing Technology in Higher Education: Strategies for Transforming Teaching and Learning. San Francisco: Jossey-Bass/John Wiley \& Co.

Bulman G. and Fairlie, R. (2016). Technology and education: Computers, software and the Internet, NBER Working Paper Series, No. 22237. http:// www. nber.org 
Chipili, C.T. Ndhlovu, D, Simui, F. (2018). Access to Career Guidance through Information and Communication Technology by Learners with Visual Impairment in Selected Secondary Schools of Zambia." Zambia ICT Journal. 2 (1), 57-65. http://ictjournal.icict.org.zm/index.php/zictjournal /article/view/54.

Creswell, J.W. (2014). Research design: Qualitative, quantities, and mixed methods approaches (4th ed.). Thousand Oaks, CA: SAGE.

Fairlie, R., \& Robinson, J. (2013). Experimental Evidence on the Effects of Home Computers on Academic Achievement among Schoolchildren, UC Santa Cruz working paper.

Global Voices. (2020). How COVID-19 affects education for people with disabilities in Ghana. https://globalvoices.org/2020/07/03/howcovid-19-affects- education-for-people-with-disabilities-ingha na/.

Henaku, A.E. (2020). Online learning experience of college students: The case of Ghana. International Journal of Multidisciplinary Sciences and Advanced Technology, 2(1), 54-62.

IFS, (2020). Learning during the lockdown: real-time data on children's experiences during home learning. http://dx.doi.org/10.1920/BN.IFS.2020.BN0288.

Ilonga, A., Ashipala, D.O., Tomas, N. (2020). Challenges experienced by students studying through Open and Distance Learning at a Higher Education Institution in Namibia: implications for strategic planning. International Journal of Higher Education, 9(4), 116-127.

Johnson-Jones, K.J. (2017). Educating Students with Visual Impairments in the General Education Setting. Dissertations. https://aquila.usm.edu/dissertations/1337

Kaisara, G. and Bwalya, K.J. (2021). Investigating the E-Learning Challenges Faced by Students during Covid-19 in Namibia. International Journal of Higher Education 10 (1).

Kaumba, M., Mphahlele, R.S., Muleya, G., Simui, F. (2021). Disablers and enablers in the uptake of information communication technologies in rural primary schools of Mwinilunga District, Zambia., Journal of Educational Technology \& Online Learning, 4(1), 1-10.

Mahyoob, M. (2020). Challenges of e-Learning during the COVID19 Pandemic Experienced by EFL Learners. Arab World English Journal (AWEJ), 11(4), 351-362.

Mukelabai, M.G, Siakalima, D., Simalalo, M., Muleya, G., Kaputa, T.M., and Simui, F. (2020). International Perspectives on Preparing PreService Teachers for Inclusive Education Pedagogies: Implications for Developing Countries. American Journal of Educational Research, vol. 8, no. 12: 885- $\quad 892 . \quad$ doi: 10.12691/education-8-12-1.

Muleya, G. Simui, F. Mundende, K. Kakana, F. Mwewa, G. \& Namangala, B. (2019). Exploring learning cultures of digital immigrants in technologically mediated postgraduate distance learning mode at the University of Zambia. Zambia Informational Communication Technology (ICT) Journal, 3(3), $1-10$.

Muwanguzi, S., \& Lin, L. (2010). Wrestling with Online Learning Technologies, International Journal of Distance Education Technologies, 8(2), 44-54.

Mwase, D., Simuyaba, E., Mwewa, G., Muleya, G., Simui, F. (2020). Leveraging Parental Involvement in the Education of their Children as a Conflict Resolution Strategy in Selected Secondary schools, Zambia, International Journal of Research and Innovation in Social Science (IJRISS), 4(7).

Patricia, L. (2017). Research Design: Quantitative, Qualitative, Mixed Methods, Arts-Based, and Community-Based Participatory Research Approaches. New York: Guilford Press.

Pauline, C.A., \& Raj, A. M. (2018). E-Learning Journal of Applied and Advanced Research, 3 (1) S11-S13.

Pogrund, R.L. (2018). Accommodations and modifications for individuals with visual impairments: Too many or not enough? Journal of Visual Impairment \& Blindness, $112,299-301$.

Redmond, P. (2011). From Face-to-face teaching to online teaching: Pedagogical transitions. In G. Williams, Statham, N. Brown and
B Cleland (Eds.), Changing Demands, Changing Directions. Proceedings ascilite Hobart (pp. 1050-1060).

Romney, G., \& Celeste, T. (2015). Experiences in developing an online teaching tool in support of evidence-based practice. Health Inform, 24(2), 9-12.

Ruchi, P. Armstrong, H., Murray, I. (2013). E-Learning for the Vision Impaired: A Holistic Perspective. International Journal of Cyber Society and Education, 6(1), 15-30.

Salmon, G. (2013). Five-stage model of online learning. http:// www. gilly salmon. com/five-stage-mo del.html

Simalalo, M. (2017). Assessing the Expanded Core Curriculum for Learners with Visual Impairments in Special Schools [Unpublished doctoral dissertation]. UNISA, Pretoria, South Africa.

Simui, F. (2018). Lived Experiences of Students with Visual Impairments at Sim University in Zambia: A Hermeneutic Phenomelogical Approach [Unpublished doctoral dissertation]. University of Zambia. http://dspace.unza.zm/handle/123456789/5884

Simui, F., Kasonde-Ngandu, S., Nyaruwata, L.T. (2017). ICT as an nabler to Academic Success of Students with Visually Impaired at Sim University: Hermeneutics Approach. Zambia Information Communication Technology (ICT) Journal, 1(1), 5-9.

Simui, F., et al. (2018). WhatsApp" as a Learner Support tool for distance education: Implications for Policy and Practice at University of Zambia, Zambia (ICT) Journal, 2(2), 36-44. http://ictjournal.icict.org.zm/index.php/zictjournal/article/view/5 5

Wagner, N., Hassanein, K., Head, M. (2008). Who is responsible for elearning in higher education? A Stakeholders' Analysis. Educational Technology \& Society, 11(3), 26-36.

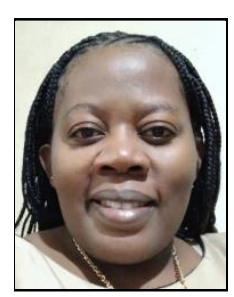

Esnart Mwanza has 17 years' experience of teaching and 2 years' experience of being a Standards officer in charge of Special Education within the Ministry of Education in Zambia. She has the passion for learners with disabilities. She holds a Certificate in primary teaching, Diploma in special Education, Bachelor of Education in Special Education and Civic Education and currently pursuing Master of Education in Special Education at the University of Zambia.

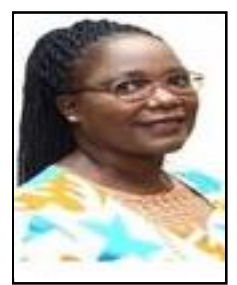

Magdalene Simalalo is a Doctor of Education in Inclusive Education from the University of South Africa. Currently a lecturer, researcher and consultant in special/inclusive education at the University of Zambia, she has been teaching and training teachers in special and inclusive education for over 14 years. Has coordinated the provision of services for students with disabilities at the University of Zambia aimed at enhancing inclusiveness.

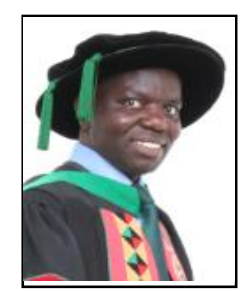

Francis Simui serves as a Senior Lecturer with keen interest in the welfare of the vulnerable persons who has served the University of Zambia in various capacities. Has vast experience in ODL Quality Assurance, having been part of the core team, which developed the SADC ODL M \& E Framework, Zambian ODL Framework and University of Zambia ODL Policy. Francis is a member of the Advisory Board of the Network of Open Educational Resources \& Multimodal SelfDirected Learning in Southern Africa through North-West University, South Africa. 